\title{
Erratum to: A novel esterase Sso2518 from Sulfolobus solfataricus with a much lower temperature optimum than the growth temperature
}

\author{
Jianjun Wang · Jiayi Wang $\cdot$ Xiangyu Gong • \\ Guojun Zheng
}

Published online: 13 May 2010

(C) Springer Science+Business Media B.V. 2010

\section{Erratum to: Biotechnol Lett \\ DOI 10.1007/s10529-010-0261-5}

Unfortunately, in the original publication the last line in the Table 1 of the lipase activity has been mistakenly set wrong, the correct version of the Table 1 is shown below.
Table 1 Specific activity for hydrolysis of various substrates

\begin{tabular}{lc}
\hline $\begin{array}{l}\text { Substrate } \\
\text { (Carbon chain length) }\end{array}$ & $\begin{array}{l}\text { Specific activity } \\
(\mathrm{kU} / \mathrm{mg})\end{array}$ \\
\hline p-NP acetate $(\mathrm{C} 2)$ & $36.3 \pm 5.4$ \\
p-NP butyrate $(\mathrm{C} 4)$ & $44.6 \pm 3.4$ \\
p-NP caproate $(\mathrm{C} 6)$ & $105.6 \pm 5.4$ \\
p-NP laurate $(\mathrm{C} 12)$ & $41.5 \pm 5.3$ \\
p-NP tetradecanoate(C14) & $4.6 \pm 2.1$ \\
p-NP oleate $(\mathrm{C} 18: 1)$ & $2.4 \pm 1.5$ \\
p-NP stearate $(\mathrm{C} 18: 0)$ & $2.1 \pm 0.8$ \\
Olive oil & $41.9 \pm 12.1 \times 10^{-3}$ \\
\hline
\end{tabular}

The online version of the original article can be found under doi:10.1007/s10529-010-0261-5.

J. Wang

State Key Laboratory of Microbial Resources, Institute of Microbiology, Chinese Academy of Sciences,

Beijing 100101, People's Republic of China

J. Wang $\cdot$ X. Gong $\cdot$ G. Zheng $(\bowtie)$

State Key Laboratory of Chemical Resources

Engineering, Beijing University of Chemical Technology,

Beijing 100029, People's Republic of China

e-mail: zhenggj@mail.buct.edu.cn 